\title{
Why who cleans counts. What housework tells us about American family life.
}

\author{
Ádám Bencze ${ }^{1}$ \\ Recommended citation: \\ Bencze, A. (2020). Why who cleans counts. What housework tells us about American family life by Shannon N. Davis \\ and Theodore N. Greenstein. Central European Journal of Educational Research, 2(3), 102-104. https://doi.org/ \\ 10.37441/CEJER/2020/2/3/8535 \\ Bibliography of the reviewed book: Davis, N. Shannon and Greenstein N. Theodore (2020). Why who cleans counts. \\ What housework tells us about American family life. Location: Policy Press Chicago. 172 pp., ISBN: 978-1-4473-3674- \\ 7
}

\section{Introduction}

In this book review, I will present the book by Shannon N. Davis and Theodore N. Greenstein, which was published in 2020. This topic is an integral part of people's daily lives. Their research examined how American heterosexual couples divide the housework among themselves. The idea for the book came from the cover of Time magazine, which was published in August 2011. In this article, the authors argued that the distribution of full-time work is equal between men and women, taking into account both paid labor (that is, men's and women's market work) and unpaid labor (non-market work, principally housework). This finding did not correspond to the experiences of the average American people in their daily lives. Nor did it with the accepted fact that women do more housework than men. We know from sociological research that the participation of women in the labor market is steadily increasing, while men play an increasingly important role in household chores. The authors were motivated by a discussion in Time Magazine to examine the distribution of housework within the family. In their book, the authors take a special approach to housework. Housework is seen as a manifestation of the power dynamics in a couple. Through housework, they write about the power dynamics between American heterosexual couples and ultimately about the functioning of American families. The combination of housework and power dynamics in this way is novel in this field.

According to the authors, housework as a social institution is about more than just washing dishes after dinner. Housework and its distribution and the way it is distributed say a lot about the relationships between heterosexual couples, but also about the systems of relationships between women and men, inequalities and the values, principles and perceptions associated with them. The authors examine the power and its dynamics as a central concept in their analysis. They start from the premise that housework is seen by everyone as an unwelcome activity, i.e. the less you do the better. How women and men can escape the compulsion to do housework depends on the power dynamics between the members of the couple. According to the authors, the power of people in this situation is mainly determined by their status on the labor market and the number of hours they have worked in the world of paid work. If we look at housework in this way, we can see that the reasons for who washes dishes after dinner are due to inequalities between women and men, the world of values and the latent power dynamics in a couple. Inequalities, values and power in a society are worth talking about constantly in everyday life and it is worth doing research in the world of science. The authors write about all these important topics in their book. The housework as an institution helps them to understand the topic.

\section{Review}

Following the introduction, the authors examine the theoretical approach to housework as power dynamics from a historical perspective. In the second chapter, the authors explain the relationships between housework and power dynamics in a couple. The authors describe housework as something that everyone wants to avoid. They further describe that, in their opinion, power can come from two sources: one material and one ideological. The material comes from the paid labor position. Power is based on the paid working time and the resources

${ }^{1}$ University of Debrecen, Debrecen, Hungary; benczeadam324@gmail.com 
gained through paid work. The other source is social, psychological, symbolic and ideological. This source builds on traditionally existing gender ideologies. Couples can rely on these two sources of power in the race to avoid housework. They can be referred to them in latent and manifest forms.

The third chapter shows that the authors base the empirics of their book on data from three waves of the National Survey of Families and Households (NSFH) collected in 1987/88, 1992/94, and 2001/2003. These were qualitative (interview) surveys, representing the whole country, conducted in couples in 13,008 households. The authors limited their analysis to heterosexual couples and could only use cases where complete household material was available from both the main respondent and their spouse / partner. This resulted in 3906 couples. The authors admit that in the thirty years between the first data and the publication of their book, the parameters of the housework have changed, but it is not the intention of the authors to describe them. Using these data they want to describe the relationship between housework and power, which, according to the authors, has not changed in these thirty years. In this chapter, the authors placed housework in a social and historical context based on NSFH data. The distribution and inequalities of household work from the late 1980s were presented. Their analysis showed that gender is the best predictor of how much housework a person does. Women did twice as much housework as men during this period. This division was slightly nuanced by education, income, place of residence, age, religious affiliation and form of cohabitation.

In the fourth chapter, the authors describe how the 3906 couples were divided into five classes using latent profile analysis (LPA) based on data from the first wave of the NSFH collected in 1987/88. These five classes were defined by the authors by examining the average time spent by women and men on nine types of housework. Housework was categorized by the authors into traditionally feminine tasks, neutral tasks and traditionally masculine tasks. During the analysis, five classes were formed to show how couples divide their time between housework tasks. The five classes are: ultra-traditional, traditional, transitional husbands, egalitarian, and egalitarian high workload. Ultra-traditional couples divided housework by gender. Women in this category spend much more time on traditionally feminine tasks, while wives spend an average of 47 hours a week on this type of housework, compared to 3.4 hours for their husbands. Traditional couples are also characterized by gender. Wives spend more time on traditional feminine tasks, while husbands spend more time on traditional masculine tasks. They shared the tasks more evenly than ultra-traditional couples, with women doing about twice as much housework as men. In addition, male members of ultra-traditional couples spent significantly more time gardening than male members of traditional couples. In transitional husbands couples, the behaviour of men is the determinant of the group, located between the two traditional and two equality groups. The gender-specification for the distribution of housework is already weakening in this group, as women do about one and a half times as much domestic work as men. In egalitarian couples the housework is evenly distributed. And even less typical is the gendered segregation of duties. Egalitarian high workload couples reverse the burden of housework, and men do more housework than women. Husbands and wives in this group spend almost as much time as traditionally female housework. Egalitarian high workload couples reverse the burden of housework, and men do more housework than women. Husbands and wives in this group spend almost same amount of time traditionally feminine housework.

In the fifth chapter, the authors deal with the characteristics of the housework class. They write about why some couples come into the categories, and what characterizes these categories. They describe that the number of hours in the paid labor market and the prestige of the position held there fundamentally determines who has to do how much housework at home. Female members of ultra-traditional couples worked the fewest hours outside the home, they also had the lowest income and the lowest professional prestige. The same applies to male members of egalitarian high workload couples. This shows that low income, low professional prestige and hours of work outside the home are strongly related to time and the distribution of housework. Female members of transitional husbands couples worked the most hours outside the home had the highest incomes, professional prestige, and education. The authors describe that both women and men have the most traditional ideologies in the ultra-traditional couples, while both women and men profess the least traditional ideologies in the transitional husbands couples. Couples who do not belong to the same ideology are more likely to belong to a group that reflects the male ideology.

In the sixth chapter, the authors examine two areas in which there are power dynamics between members of couples. One is the economic area with paid labor hours and prestige, the other is the field of conflict from disagreement to physical violence. All five groups have a latent power game about the distribution of housework with the help of paid work and the prestige. The possibilities of a female member of an ultra-traditional couple and an egalitarian couple are obviously different. Most disagreements were reported by members of egalitarian high workload couples, while the fewest were reported by members of the traditional couples and the ultra- 
traditional couples. It can also illustrate how the power dynamics can affect the lives of couples. Where the relationship between couples is more egalitarian, there are more disagreements and the paid labor situation of couples is more differentiated. The authors explain that, based on the five categories, there are differences not only in the number of disagreements, but also in the resolution of these conflicts. Relatively few couples reported intimate partner violence, so the authors were unable to distinguish between the groups.

Until the seventh chapter, the authors worked with analyses of data from the first wave of the NSFH collected in 1987/88. In seventh and eighth chapter the authors compare the data recorded in 1992/94 with earlier data. The question is whether couples remain in a group or become more traditional or equal over the years. It is interesting to note that the division of housework for most couples has changed over time. Couples were more likely to change class membership than not. However, the changes did not happen in one direction, couples became more traditional and equal. The large number of changes shows that the power dynamics between the members of the couples are constantly changing and shaping the division of housework. The changes were mainly influenced by changes in the paid labor and the permanence of gender ideologies.

The ninth chapter is based on data from the third wave of the NSFH collected in 2001/2003 when asked adult children of couples. Their question was whether the group membership of the parents influences the group membership of the adult children. According to the authors, the power dynamics is also inherited between generations. Children of the traditional and the ultra-traditional couples have been most strongly influenced by this heritage. The male adults in traditional couples were the least marked by egalitarian attitudes.

\section{Conclusions}

As I mentioned in the introduction, this book is not only about who washes dishes after dinner and why. There are much deeper social, historical and psychological reasons for the distribution of housework, based on issues affecting society as a whole. Like issues of equality and inequality, gender and power. However, these general concepts are easier to grasp if we examine them in relation to a specific social phenomenon, in this case housework. To sum up the book contributes to the solution of the research problem with data from a representative qualitative longitudinal study with a large sample. The novelty of the book is a comprehensive account of the relationship between housework and power and an examination of the further inheritance of this power dynamics. The authors' style is supple, they presented the subject in an interesting and varied way. The appearance of illustrations, diagrams and graphs is sophisticated. Bibliographies and appendices are data-rich and accurate. I particularly recommend them to professionals who study families, the relationship between women and men and gender inequalities. In a broader sense, for professionals who study aspects of equality, inequality, freedom, justice and power. And finally, for those who just wonder who washes dishes after dinner and why.

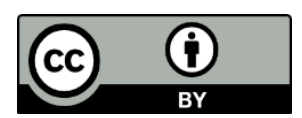

(C) 2020 by the authors. Submitted for possible open access publication under the terms and conditions of the Creative Commons Attribution (CC BY) license (http://creativecommons.org/licenses/by/4.0/). 